\title{
Effect of Hydrogen Peroxide Concentration on $100 \%$ Cotton Knit Fabric Bleaching
}

\author{
Jannatul Ferdush, \\ Kamrun Nahar, \\ Tarifun Akter, \\ Most. Jannatul Ferdoush, \\ Nusrat Jahan, \\ Lecturer, Northern University Bangladesh, Bangladesh
}

S.M Farhana Iqbal,

Head, Department of Yarn Engineering,

Bangladesh University of Textiles, Bangladesh

Doi:10.19044/esj.2019.v15n33p254 URL:http://dx.doi.org/10.19044/esj.2019.v15n33p254

\begin{abstract}
This paper focuses on the effect of different concentration of hydrogen peroxide (an oxidizing bleaching agent) on 100\% single jersey cotton knit fabric. Five different concentrations $(25 \%, 30 \%, 35 \%, 40 \%$ and $45 \%)$ of hydrogen peroxide solution (5\% stock solution) were adopted for this experiment. For each individual concentration, bleaching was performed in three different quantities $(6 \mathrm{gm} / \mathrm{L}, 8 \mathrm{gm} / \mathrm{L}$ and $10 \mathrm{gm} / \mathrm{L})$ at the same temperature $\left(100^{\circ} \mathrm{C}\right)$ and same time $(60$ minute) cycle. $5 \mathrm{gm}$ samples were taken where 1:10 material and liquor ratio was maintained in each operation. Spectrophotometer (data color 650) was used to test the reflectance of all bleached samples, and their bursting strengths were measured by an Auto burst instrument following ISO 13938-1 method. The effects of hydrogen peroxide concentration on various physical properties such as weight loss, absorbency, GSM, bursting strength, and whiteness was studied to minimize the cost of bleaching process by optimizing the concentration of hydrogen peroxide. As majority of industries have concerned to alineate the production cost with maximum quality assurance which has been obtained through bleaching at 30\% concentration.
\end{abstract}

Keywords: Cotton fabric, Peroxide bleaching, Whiteness index, Reflectance

\section{Introduction}

Bleaching is the process of removing natural color from textile substrate, which yields a permanent white color of yarn or fabric. Thus, the 
results of dyeing would be accurate. It is the process of destroying natural coloring matter from the textile materials to achieve a clean white end product. This is a second step of pretreatment of textile materials as well as wet processing technology. Owing to the presence of protoplasmic residues of the protein and flavones pigments of cotton flowers, it possesses its natural grey color (Abdel-Halim, 2012). As a consequence, it needs to pre-treat the cotton to produce a perfect white surface that is suitable for dyeing or any other wet process treatment (Kabir et al., 2014). Hydrogen peroxide is the most commonly used bleaching agent among all others, since it can bleach both cellulosic and protein fibers successfully (Trotman, 1975). It is a slightly more viscous and colorless liquid whose chemical formula is $\mathrm{H}_{2} \mathrm{O}_{2}$, with high sensitivity to metal ions. It is primarily used as an oxidizer, bleaching agent, and disinfectant. Although there is no exact evidence in the case of the nature of bleaching action of hydrogen peroxide, it is believed that the per-hydroxyl ion is the active group. Formation of this ion happened when hydrogen peroxide cleaves into the following manner (Wyszecki et al., 1982).

$$
\begin{gathered}
\mathrm{H}_{2} \mathrm{O}_{2} \longrightarrow \mathrm{H}^{+}+\mathrm{HO}_{2}^{-} \\
\mathrm{HO}_{2}-\longrightarrow \mathrm{HO}^{-}+[\mathrm{O}]
\end{gathered}
$$

In the absence of any kind of hue, high luminous color of material gives an aspect of whiteness index (Zollinger, 2003). White is a monochromic color, and it is categorized by constant absorption from 400 to $700 \mathrm{~nm}$ wave length. Whiteness is a parameter of an ideal reflecting surface area that neither absorbs nor transmits light. On the contrary, it reflects light at equal intensities in all directions. In 1981, CIE recommended a formula which is known as "CIE Whiteness." These indices are specified by the CIE under the illuminant D65 and illuminant C combined with standard observer (either $2^{\circ}$ or $10^{\circ}$ observer). Performance of bleaching effect is also determined by reflectance. This reflectance can be measured by "Spectrophotometer" or "Reflectometer". Here, reflectance value 100 means a perfect white whereas 0 means perfect black. Saravanan and Ramachandran carried out an experiment of the bleaching actions of hydrogen peroxide which was synthesized from glucose oxidase enzyme after it was applied on cotton fabric. However, glucose oxidase had revealed lower value whiteness than what was expected in the commercial processes (Saravanan, 2010). Abdul and Narendra worked on a project of accelerating bleaching actions on cotton by using hydrogen peroxide. In their empirical work, they analyzed that enhancing temperature can exalt the rate of bleaching and can also reduce the process time. In addition, due to the accelerating concentration of peroxide, whiteness may also be increased but the weight of material will decrease. According to them, water hardness and stabilizer concentration can reduce whiteness but increase weight loss (Abdul, 2013). For the perfect bleaching of cotton fabric, some weight loss of cotton fabric will definitely happen. Abdul and Narendra, in 
their study, found that with the increase in the concentration of bleaching agent, whiteness index increases but the weight of material decreases (Abdul, 2013). The investigation of Kumbasar et al. on hydrophobicity and whiteness index shows that with the increase of hydrogen peroxide and activator concentration, hydrophobicity and whiteness also increase (Sonaje, 2013). Nasser et al. tried to optimize different parameters of bleaching like temperature, time, and peroxide concentration in the case of whiteness index and bursting strength of the knitted cotton fabric, and they observed an inverse relation between them (Naser, 2015).

This study emphasize the optimum concentration of hydrogen peroxide to achieve permanent whiteness with minimal loss of fabric strength during bleaching procedure. Reduction of chemicals leads towards a cost reduction process. In addition, it has been measured reflectance, GSM, absorbency test of bleached sample to determine an accurate concentration resulting precision dyeing.

\section{Material and Methods}

Substrate

Fabric Type: Single jersey

Fabric Construction

Composition- $100 \%$ cotton

CPI- 42;WPI-60

Yarn count- $28 \mathrm{Ne}$, Loop length-2.4mm

GSM-160

Color: Grey

Recipe of bleaching

$\begin{array}{cc}\text { Sample weight } & 20 \mathrm{gm} \\ \text { Wetting agent } & 2 \mathrm{gm} / \mathrm{L} \\ \text { Sequestering agent } & 2 \mathrm{cc} / \mathrm{L} \\ \text { Detergent } & 3 \mathrm{cc} / \mathrm{L} \\ \text { Caustic soda } & 6 \mathrm{cc} / \mathrm{L} \\ \text { Hydrogen per oxide } & 10 / 8 / 6 \mathrm{cc} / \mathrm{L} \\ (25 / 30 / 35 / 40 / 45) \% & \\ \text { Stabilizer } & 2 \mathrm{cc} / \mathrm{L} \\ \text { (Sodium silicate) } & \\ \text { Temperature } & (90-100)^{0} \mathrm{C} \\ \text { Time } & 60 \mathrm{minutes} \\ \text { pH } & 11 \\ \text { M: } \mathrm{L} & 1: 10\end{array}$




\section{Bleaching Procedure}

Bleaching of grey fabric was done in a closed vessel for 1 hour at $100^{\circ} \mathrm{C}$ keeping the material to liquor ratio at 1:10 with hydrogen peroxide (6$10 \mathrm{cc} / \mathrm{l})$, sodium hydroxide $(6 \mathrm{cc} / \mathrm{l})$, sodium silicate $(2 \mathrm{cc} / \mathrm{l})$, and none ionic detergent $(3 \mathrm{gm} / \mathrm{L})$. The $\mathrm{p}^{\mathrm{H}}$ of the bath was maintained at 11 . Then it was rinsed thoroughly with hot and cold water and subsequently dried in air.

\section{Different Test Methods}

\section{Measurement of Whiteness Index (WI)}

The cotton bleached fabrics were tested through a spectrophotometer (data color 650, USA) in order to determine the whiteness index at D65 illuminant and $10^{\circ}$ observer setting.

\section{Weight Loss Measurement}

Percentage of weight loss occurred in the cotton knit fabric due to bleaching which was evaluated by oven dry-weight basis. Usually, it is calculated from the following equation which shows the difference of pretreated and treated sample weight. It is also measured in percentage of pretreated weight of the of the sample.

$$
\text { Weight loss }=\frac{\mathrm{W}_{1}-\mathrm{W}_{2}}{\mathrm{~W}_{1}} \times 100
$$

\footnotetext{
Absorbency Test

The absorbency test of bleached sample was performed by drop test and wicking test according to the established procedure.

* Drop Test

In a pipet, water is taken and water drops are dropped on the scoured fabric. Then the absorption of the water drop is observed visually.

* Wicking Test

In a beaker, $1 \%$ direct dye red color is taken and a sample $(18 \mathrm{~cm} \times 5$ $\mathrm{cm})$ is cut from bleached fabric which is hung from a wood stick. This is supported by immersing that $1 \mathrm{~cm}$ portion of fabric in the dye liquor. Then the point is measured up to which the colored solution is absorbed by the sample in 5 min time.
}

\section{Bursting Strength}

All the samples were tested through a bursting strength testing instrument (Auto burst, SDL Atlas, England) followed by ISO13938-1 method. Each specimen was placed beneath the ball. It must also be flat and free from creases and any kind of distortions. Then the two clamp buttons were pressed. After that, the standard flow rate was selected. It measures the speed 
at which the ball will inflate. Then start button was pressed and the diaphragm was automatically inflated until the specimen bursts. The reading was then collected from the instrument as $\mathrm{KPa}$ unit.

\section{Result and Discussions \\ Whiteness Index of Bleached Sample}

Greater value of "STD CIE WI" indicates that sample is whiter. It is observed that the sample bleached with hydrogen peroxide at $25 \%$ concentration has higher value of STD CIE WI, while less tint variation is achieved during bleaching of hydrogen peroxide for $30 \%$ concentration. On the other hand, STD CIE WI is 162.5 for $30 \%$ concentration of hydrogen peroxide bleaching which is near to $25 \%$ concentration. Therefore, it can be said that bleaching of hydrogen peroxide at $30 \%$ concentration for $10 \mathrm{cc} / \mathrm{L}$ comparatively yields the best whiteness result.

CIE Whiteness Index

- STD CIE WI

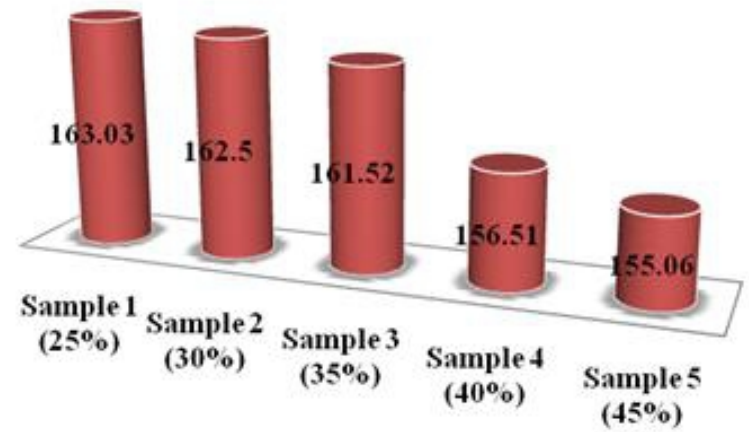

Figure 1. Whiteness index of bleached sample 


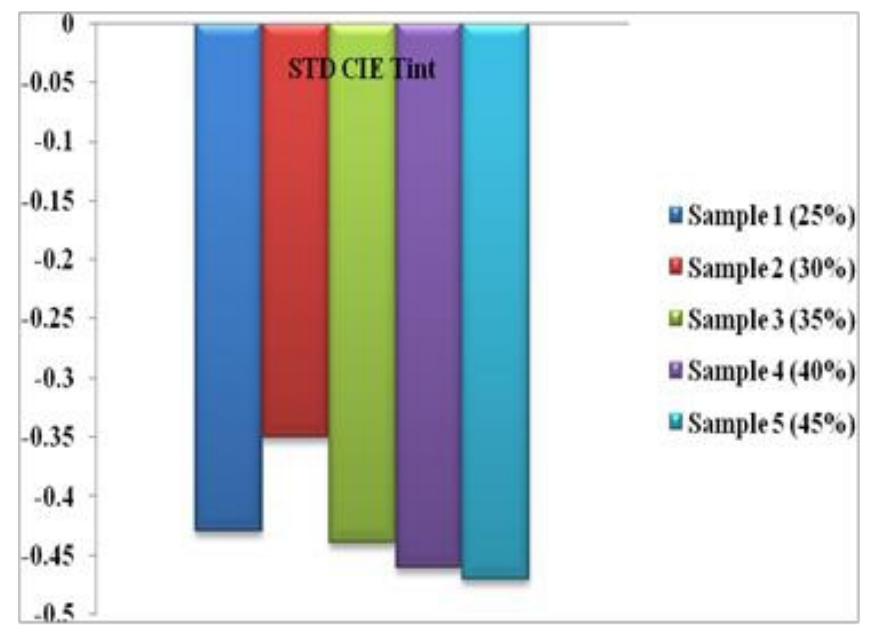

Figure 2. CIE STD Tint of bleached sample

\section{Weight Loss (\%)}

Since the standard range of weight loss percentage of bleaching is 4$8 \%$, fabric bleaching with hydrogen peroxide at $40 \%$ and $45 \%$ concentration is over bleached which creates an adverse effect on fabric. Furthermore, standard weight loss is observed in the case of $25 \%, 30 \%$, and $35 \%$ concentration of hydrogen peroxide.

= Weight loss $(\%)$

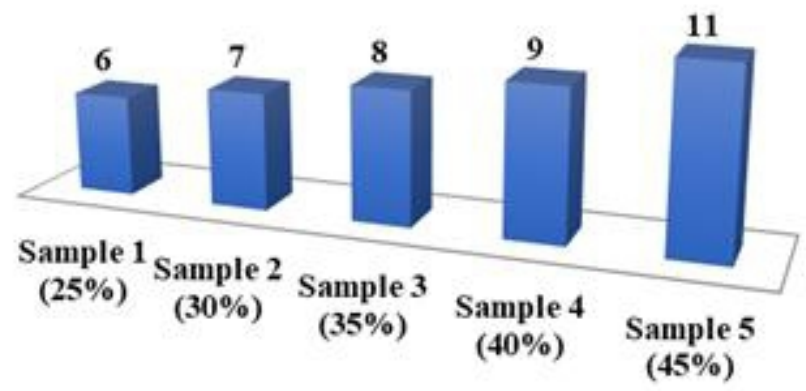

Figure 3. Weight loss (\%) of all bleached sample

\section{Variation in GSM}

Enormous GSM variation has been observed for bleaching of hydrogen peroxide at $45 \%, 40 \%$, and $35 \%$ respectively. This is not appreciated because it means that fabric is over bleached. On the other hand, GSM loss of hydrogen peroxide bleaching is 1.1 and 1.2 for $25 \%$ and $30 \%$ concentration. 
Thus, GSM fabric bleached with $25 \%$ and $30 \%$ concentration of $\mathrm{H}_{2} \mathrm{O}_{2}$ is better.

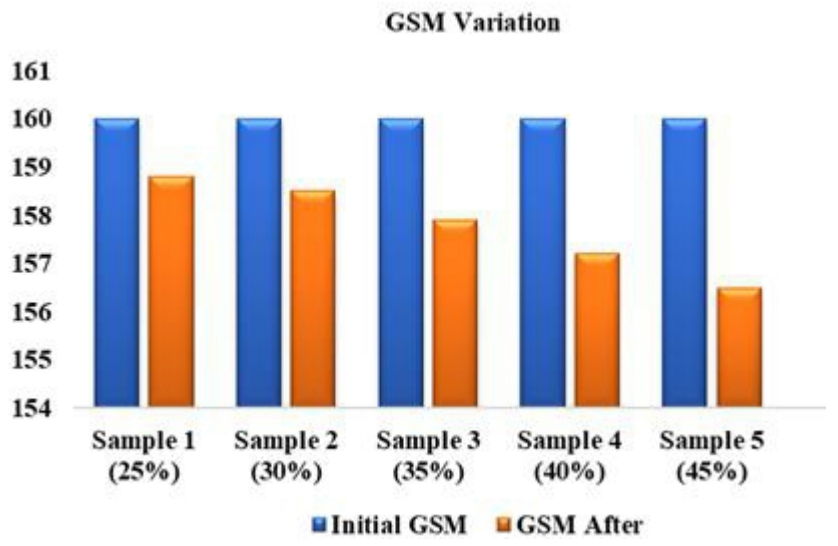

Figure 4. GSM variation of all bleached sample

\section{Absorbency Test \\ * Drop Test}

From the drop test results, it has been observed that fabric bleached with hydrogen peroxide at $25 \%$ concentration takes more time to absorb the droplet. At 30\% and 35\% concentration, $4 \mathrm{sec}$ is required to absorb the drop, while $3 \mathrm{sec}$ is needed for $40 \%$ and $45 \%$ hydrogen peroxide concentration of bleached fabric.

Table 1. Test result of drop test of all bleaching samples

\begin{tabular}{|l|l|l|l|}
\hline $\begin{array}{l}\text { Sample } \\
\text { No. }\end{array}$ & $\begin{array}{l}\text { Concentration } \\
(\%)\end{array}$ & $\begin{array}{l}\text { Absorption } \\
\text { time before } \\
\text { bleaching } \\
\text { (min) }\end{array}$ & $\begin{array}{l}\text { Absorption } \\
\text { time after } \\
\text { bleaching } \\
\text { (sec) }\end{array}$ \\
\hline 1. & 25 & $1 \mathrm{~min}$ & 5 \\
\hline 2. & 30 & $1 \mathrm{~min}$ & 4 \\
\hline 3. & 35 & $1 \mathrm{~min}$ & 4 \\
\hline 4. & 40 & $1 \mathrm{~min}$ & 3 \\
\hline 5. & 45 & $1 \mathrm{~min}$ & 3 \\
\hline
\end{tabular}

\section{Spot Test}

The surface area of the absorption of all sample bleached with hydrogen peroxide shows the good scouring effect at 30\%, 40\%, and $45 \%$ concentration. This is according to its spot observation of dye solution as its spot are nearly round shape. 
Table 2. Pictorial view of spot test of all bleaching samples

\begin{tabular}{|c|c|c|c|}
\hline $\begin{array}{l}\text { Sample } \\
\text { no. }\end{array}$ & $\begin{array}{l}\text { Concentration } \\
(\%)\end{array}$ & Spot observation & Comment \\
\hline 1 & 25 & & Irregular \\
\hline 2 & 30 & & Round \\
\hline 3 & 35 & & Round \\
\hline 4 & 40 & & Round \\
\hline 5 & 45 & & Round \\
\hline
\end{tabular}

\section{Wicking Test}

The absorbed length of $45 \%$ concentration of peroxide bleached sample is $55 \mathrm{~mm}$. This sample shows the over bleaching than other concentration of peroxide bleached sample. On the other hand, fabric bleached at $35 \%$ and $45 \%$ shows very good results as they wick $43 \mathrm{~mm}$ and $48 \mathrm{~mm}$ dye solution. In addition, 30\% concentrated hydrogen peroxide gives good 
bleaching effect as it can wick $37 \mathrm{~mm}$ dye solution after passing through wicking test.

Table 3. Wicking test results of bleached samples

\begin{tabular}{|c|c|c|c|}
\hline $\begin{array}{c}\text { Sample } \\
\text { No. }\end{array}$ & $\begin{array}{c}\text { Concentration } \\
(\boldsymbol{\%})\end{array}$ & $\begin{array}{c}\text { Absorbed Length of dye } \\
\text { solution in bleached } \\
\text { fabric(mm) }\end{array}$ & Comment \\
\hline 1. & 25 & 30 & Average \\
\hline 2. & 30 & 37 & Good \\
\hline 3. & 35 & 43 & Very good \\
\hline 4. & 40 & 48 & Very good \\
\hline 5. & 45 & 55 & $\begin{array}{c}\text { Over } \\
\text { bleached }\end{array}$ \\
\hline
\end{tabular}

\section{Bursting Strength}

After analyzing the bursting test of cotton bleached fabric properly, it has been seen that fabric bleached with $40 \%$ hydrogen peroxide shows the lower bursting strength. On the contrary, 25\% concentrated bleaching agents yield high bursting results which is more than $410 \mathrm{Kpa}$. However, $407 \mathrm{kPa}$ strength is noticed in the case of $30 \%$ and $35 \%$ concentration of hydrogen peroxide as bleaching agents which is acceptable.

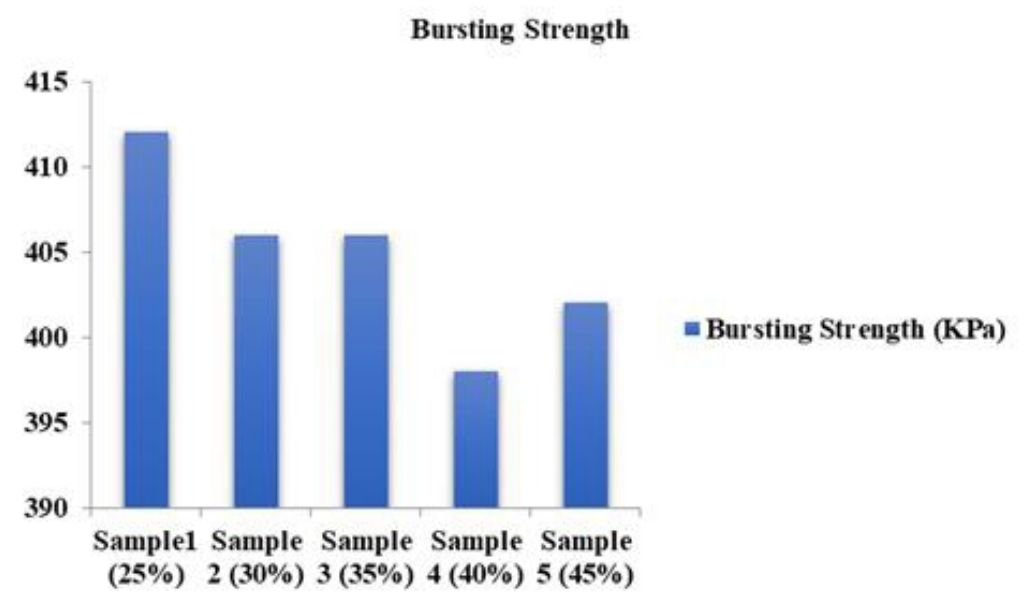

Figure 5. Bursting strength testing

\section{Conclusion}

In this study, the effect of different concentrations of hydrogen peroxide on cotton fabric bleaching was investigated. Five different concentrations with three variables of quantity were used to analyze the effect of bleaching. Bleaching with hydrogen peroxide provided best results with $30 \%$ concentration which can minimizes the cost of bleaching process as most of the industry uses higher concentration of $\mathrm{H}_{2} \mathrm{O}_{2}$. Though $40 \%$ concentration also provided good results but it enhance the process cost of pre-treatment. 


\section{References:}

1. Abdel-Halim, E. S. (2012). Simple and economic bleaching process for cotton fabric. Carbohydrate Polymers, 88, 1233-1238.

2. Abdul, S. B. \& Narendra, G. (2013). Accelerated Bleaching of Cotton Material with Hydrogen Peroxidell, J Textile Sci Eng, vol. 3:140, doi:10.4172/2165-8064.1000140.

3. Kabir, S. M. F., Iqbal, M. I., Sikdar, P. P., Rahman, M. M., \& Akhter, S. (2014). Optimization of parameters of cotton fabric whiteness. ESJ, 10(36), 200-210.

4. Naser, M., Haque, A., \& Islam, M. A. (2015). Optimization of bleaching parameters by whiteness index and bursting strength of knitted cotton fabric, International Journal of Science\& Technology, Vol. 4, Issue 4, pp. 40-43, 2015.

5. Sonaje, N. P. \& Chougule, M. B. (2013). Comparison of whiteness index of cotton fabric bleached with recycled waste water, International Journal of Innovative Research in Science, Engineering and Technology, Vol. 2, Issue 8, pp. 3946-3951.

6. Saravanan, D. \& Ramachandran, T. (2010). Bleaching of cotton fabrics using hydrogen peroxide produced by glucose oxidasell, Indian Journal of Fiber\& Textile Research, vol. 35, pp. 281-283.

7. Trotman, E. R. (1975). Dyeing and chemical technology of textile fibres. Bucks: Charles Griffin \& CO. Ltd.

8. Wyszecki, G. \& Stiles, W. S. (1982). Color science: Concepts and methods, quantitative data and formulae. New York: JohnWiley.

9. Zollinger, H. (2003). Color chemistry, syntheses, properties, and applications of organic dyes and pigments. New York:Wiley-VCH. 